University of California, Hastings College of the Law UC Hastings Scholarship Repository

Faculty Scholarship

1987

\title{
Taking Kawashima Seriously: A Review of Japanese Research on Japanese Legal Consciousness and Disputing Behavior
}

Setsuo Miyazawa

UC Hastings College of the Law, miyazawa@uchastings.edu

Follow this and additional works at: http://repository.uchastings.edu/faculty_scholarship

Part of the Law Commons, and the Sociology Commons

\section{Recommended Citation}

Setsuo Miyazawa, Taking Kawashima Seriously: A Review of Japanese Research on Japanese Legal Consciousness and Disputing Behavior, 21 Law \& Soc'y Rev. 219 (1987).

Available at: http://repository.uchastings.edu/faculty_scholarship/1217 


\title{
TAKING KAWASHIMA SERIOUSLY: A REVIEW OF JAPANESE RESEARCH ON JAPANESE LEGAL CONSCIOUSNESS AND DISPUTING BEHAVIOR
}

\author{
SETSUO MIYAZAWA
}

\begin{abstract}
This paper discusses Japanese research on legal consciousness (ho-ishiki) and civil disputing. The author presents a recent explication of Takeyoshi Kawashima's concept of legal consciousness as a cultural factor and also proposes to explore the possibility of treating it as an individual, attitudinal factor. He also reviews large-scale surveys of aggregate-level culture and studies on individual-level disputing behavior. The need and possibility of a longitudinal study of individual disputing behavior that uses individual-level attitudes and regional culture as explanatory variables is suggested.
\end{abstract}

\section{INTRODUCTION}

In Japan, the subject of this paper has been called hoishiki, or "legal consciousness."* This term was used in an article title as early as 1935 (Rokumoto, 1983b: 26). Legal consciousness has been so dominant an issue in subsequent Japanese law and society scholarship, particularly during the past twenty years, that the Japanese Association of the Sociology of

An earlier version of this paper was presented at the 1986 annual meeting of the Law and Society Association held in Chicago from May 29 to June 1, 1986. It was prepared upon an invitation from Malcolm M. Feeley, a member of the program committee for that meeting. The author is grateful to J. Mark Ramseyer and Antoine Chalhoub for their assistance in editing that paper. The Japanese Ministry of Education provided a travel grant for the meeting. This slightly modified version benefited from comments from Jim Inverarity and encouragement and assistance from the editor and the production editor of this journal.

* Kawashima (1982: 404-405) opposes the translation of ho-ishiki as "legal consciousness." He says that he meant to include subconscious as well as conscious elements of psychological phenomena, that his concept is based not on psychology but on the sociology of culture or anthropology, and that he used ho-ishiki as a convenient term to mean "a broader mental life as a whole." He complains that he has been bewildered by and felt responsible for the misleading translation of "legal consciousness" and approvingly refers to the French translation of ho-ishiki as "mentalite." His protest notwithstanding, I use "legal consciousness" simply as the most conventional term for the subject. 
Law (JASOL) chose it as the theme of its annual meetings from 1982 to 1984. Someone should introduce the Japanese scholarship on this subject to international colleagues. I would like to perform this role.

With the publication of Kawashima's article "Dispute Resolution in Contemporary Japan" (1963), Japan was represented to international readers as a country with the apparently contradictory combination of rapid industrialization and extremely few litigated cases and lawyers. Kawashima then made a fuller presentation of his thesis in Japanese (1967, 1974 [for a partial English translation]). He was interpreted as explaining this anomaly in terms of the traditional legal consciousness that regarded the mobilization of the formal legal system as a threat to social harmony and held a moralistic aversion to litigation. Such a view quickly became the accepted wisdom both abroad and at home.

Some foreign readers, particularly American Japanologists in the field of law, no longer accept that view. Haley (1978, 1982) criticized it as "the myth of the reluctant litigant" and presented an alternative that explained the relative infrequency of the mobilization of the formal legal system by institutional factors that discouraged the use of law. Since then, revisionist interpretations have been presented by younger generations of Japanologists (for most recent examples, see Bryant, 1984; Ramseyer, 1985a, 1985b; Upham, forthcoming). Even nonspecialist law and society scholars have started to doubt the conventional view of Japanese legal consciousness (on the different responses of pollution victims supposedly holding the traditional consciousness, see Kidder, 1983: 45-51; Galanter, 1983: 57).

However, there are still authors who describe the Japanese legal system as "the law of the subtle mind" (Kim and Lawson, 1979). Moreover, people such as former Supreme Court Chief Justice Warren Burger and Harvard President Derek Bok who are critical of American litigiousness and who advocate the introduction of informal means of dispute resolution seem to look to Japan for a model (Ramseyer, 1985b: 604; Upham, forthcoming: 320-323). Favorable interest in Japan may also come from those who criticize the legalistic administrative process in the United States (Stewart, 1981; Harvard Law Review, 1981). Japanese-style administrative guidance may become their inspiration (Johnson, 1982).

Given this division among international scholars, empirical Japanese research may be of particular interest. Unfortunately, probably due to the domination of law teachers in law 
and society scholarship in Japan, we have not yet accumulated as much information as we need nor formed a consensus among ourselves. In fact, one of the organizers of the JASOL conventions (Toshitani, 1985: 9) concluded after the first two meetings on legal consciousness that we are only beginning to conduct truly empirical studies. In this paper, I will summarize our knowledge of the subject and present some preliminary ideas for future research.

\section{CONCEPTS AND PROBLEMS}

Friedman (1977: 76; see also Friedman, 1975: chaps. 8, 9) defines "legal culture to mean attitudes, values, and opinions held in society, with regard to law, the legal system, and its various parts." Legal consciousness is another term for the same concept.

We may analyze such attitudes, values, and opinions at both aggregate and individual levels. I use the term "culture" for the aggregate level and the term "attitude" for the individual level. This usage fits well the respective definitions of these concepts in anthropology and in social psychology, for in anthropology "culture" refers to the norms, rules, and standards implicit in the dominant patterns of behavior and social relationships within a group (Singer, 1968), while in social psychology "attitude" describes a learned behavioral predisposition that is consistently favorable or unfavorable to a given object (Fishbein and Ajzen, 1975).

Group culture and individual attitude may largely overlap in coverage and content. We may not, however, assume that aggregate level relationships between culture and behavioral patterns always imply the same relationships for any individual member. The impact of culture on individual behavior has to be ascertained through analysis at the individual level. To understand the impact of culture and attitude on the mobilization of formal legal systems, we need to conduct research at both levels.

In this discussion, I shall: (1) present explications of Kawashima's thesis with regard to both the proper understanding of his concept of legal consciousness (Rokumoto, 1986a, b) and the possibility of treating legal consciousness as an attitudinal factor of individual law-related behavior, (2) summarize the research on the existence and content of culture and on the processing of individual disputes, and (3) make preliminary research design proposals that reflect these explications of the Kawashima thesis and evaluations of the existing research. 


\section{EXPLICATIONS OF THE KAWASHIMA THESIS}

Haley (1978: 359) regarded Kawashima as the major proponent of the belief that "the Japanese are an exceptionally nonlitigious people." He saw Kawashima as having solved the "dilemma posed by the institutional ideal of an active judiciary in a nonlitigious society" by viewing "Japanese aversion to litigation as a gradually fading, traditional response" (ibid., p. 361). Hence, Haley criticized Kawashima by citing statistics that indicated that Japanese litigation rates were both higher than in some Western European countries and higher in Japan before the war than after it. Haley should be credited for launching the first serious criticism of the accepted view. Many Japanese scholars, including myself, soon accepted his basic argument that institutional factors that had been deliberately introduced by the elite might have more impact than culture.

Rokumoto (1986a: 193-196, 269-274) has recently criticized Haley for failing to understand the deeper meaning of the Kawashima thesis. He argues that Kawashima was discussing a general framework for perceiving and evaluating social relationships, not attitudes about a concrete system of positive law. $\mathrm{He}$ distinguishes two levels of abstraction: "legal consciousness" and the more abstract "legal conception" (ho-kannen). The former refers to the knowledge, opinions, and evaluation of the existing legal system under specific conditions, while the latter refers to a conception of law "as an abstract, ideal image" (ibid., p. 193). He also introduces a parallel typology of kenriishiki ("rights consciousness") and kenri-kannen ("rights conception"), referring respectively to knowledge, opinions, and evaluation of specific rights and to a general framework of perceiving and evaluating social relationships in terms of clear, universalistic rules that define each person's rights and are applied irrespective of the actual power relationships between the parties. According to Rokumoto, Kawashima was talking about the legal conception and the rights conception.

Kawashima (1967) in fact discusses these conceptions and applies his general thesis to specific areas such as property, contract, and civil litigation. He argues that the Japanese, unlike modern Europeans, do not conceive of their social relationships in terms of universal standards of rights and duties and that the Japanese legal consciousness reflects this form of rights consciousness. Japanese expect the law to be indeterminate in both its content and its status as a norm. Nonlitigiousness is just one result of this legal consciousness (ibid., p. 127). Although Kawashima has not responded to either Haley or 
Rokumoto, Rokumoto's explication seems fair. Nonlitigiousness may be a dependent variable of Japanese legal conception, but it is not Japanese legal conception itself (Rokumoto, 1986b).

However, Kawashima does not necessarily give us an empirical indicator of the traditional Japanese legal consciousness that was measured separately from its dependent variables. Instead, Kawashima tends to assume the traditional legal consciousness behind anecdotes presented for dependent variables and cites, for instance, judicial statistics as evidence of changes in it. Thus, Haley's criticism was also fair as it corresponded with what Kawashima was actually doing with his data. What we must measure is Japanese legal consciousness, separated from such behavioral patterns as litigation rate, at the level explicated by Rokumoto.

There is another element in Kawashima's argument, the implication of which has not been empirically explored. Although the Kawashima thesis should be fundamentally viewed as a discussion of culture, one of his justifications for his interest in legal consciousness is at the level of individual attitude (Kawashima, 1967: 6-14). At this level, legal consciousness is said to have the three components of perception, value judgment, and emotion, which evoke the three elements of attitude outlined by Rosenberg and Hovland (1960). Legal consciousness analysis is expected to provide explanations of individual law-related behavior at the closest, motivational level. While Kawashima's recent explication (1982: 404-405) emphasizes its cultural nature, I suspect that legal consciousness is more amenable to empirical research at this level than at the aggregate, cultural level. Furthermore, aggregate-level relationships between culture and behavioral patterns demand an empirical explication to understand their inherent causal relationships. We thus need empirical research at both levels.

\section{LARGE-SCALE QUESTIONNAIRE SURVEYS OF AGGREGATE-LEVEL CULTURE}

Since Kawashima's works appeared, the dominant form of analysis of the Japanese legal consciousness has been anecdotal. A critical problem with this approach is that, given the complexities of any society, one can always find some episodes that apparently support one's thesis. As part of their broader criticism of this method, for instance, Sugimoto and Mouer (1982: chap. 11) could easily find examples that suggest a description of Japan which is opposite from the standard stereotype and is instead an individualistic society where people are always en- 
gaged in dry calculation and are exposed to constant controls from the powerful.

Of course, to be persuasive, any analysis must explain our daily experiences of the real world. What we need, then, are representative data that provide a context in which anecdotal data can be properly evaluated. Questionnaire surveys have been conducted to collect such data about dominant culture. What distinguishes the Japanese surveys on legal consciousness is that, unlike their foreign counterparts (e.g., Podgorecki et al., 1973; Curran, 1977; Gibson and Baldwin, 1985), they have been expected to provide information on something more general than knowledge, opinions, and demands about the existing legal system.

Major surveys on legal consciousness have been conducted by the Nippon Bunka Kaigi (Japan Culture Forum) (1973; 1982), the Osaka Bengoshikai (Osaka Bar Association) (1977), the Kyoto Daigaku Hogakubu (Kyoto University Faculty of Law) (1978), and the Nihon Bengoshi Rengokai (Japanese Federation of Bar Associations) (1986). The last survey is particularly large (a national sample of 2,315 ) and rich (402 questions). However, its data have not yet been fully examined. Therefore, I cite samples of questions and response distributions from the Nippon Bunka Kaigi (NBK) and the Kyoto Daigaku Hogakubu (KDH) projects.

The first study by the NBK was the earliest large-scale sample survey on legal consciousness in Japan. It was conducted in 1971 and based on a representative sample of 1,053 Tokyo area residents. In 1976 NBK conducted a follow-up survey of the same area with 1,080 respondents. Table 1 presents some of the data.

The results of the surveys were ambiguous. Apparently contradictory patterns appear for Questions 15 and 16. On the one hand, notwithstanding the stereotypes about Japanese legal behavior, an overwhelming majority of respondents indicated that they preferred detailed contracts. On the other hand, a majority also indicated a rather relaxed view about the bindingness of a contract, a result consistent with the stereotype. Apparently contradictory results were also obtained for other areas, including the administration of criminal justice, and the project reporters interpreted these results to mean that the Japanese hold strict views about the formal legal system as an institution but at the same time expect flexible enforcement. They also interpreted the responses to Questions 32 and 33 to indicate flexibility. 
Table 1. Selected Questions from the Nippon Bunka Kaigi Surveys (in percent)*

1971 1976

$(N=1,053)$ $(N=1,080)$

Question 15: What would you do if a contract became unsuited to the actual situation a few years after it was made?

1. However unsuitable, a contract is a 31.6 contract, and I would abide by it.

2. I would discuss with the other party whether the contract could be ignored.

3. Don't know/no answer.

64.3

Question 16: Which statement most closely reflects your opinion?

1. Because a contract is a formality, it is better to make written contracts as simple as possible and descriptions in it as flexible as possible.

2. It is better to include as many details and concrete descriptions in a contract as possible so that a dispute will not arise.

3. Don't know/no answer.

Question 32: Which statement most closely reflects your opinion?

1. Laws should enable us to live more comfortably with each other.

2. Laws should realize justice in the

3. Don't know/no answer.

Question 33: Do you agree with the statement that "We should abide by the law of the country even if we believe it to be unjust"?

1. Agree.

2. Do not totally agree.

3. Totally disagree.

4. Don't know/no answer.

Question 42; Would you consider suing if your rights were violated?

1. Immediately.

2. Occasionally.

3. No, unless the matter were extremely

4. Don't know/no answer.

Question 43: Do you agree with the statement that "Litigation is expensive and time-consuming, and even when you win, you will usually lose money"?

1. Agree.

2. Disagree.

3. Don't know/no answer.

* Unfortunately the authors of these studies have not provided tests of significance of differences in these data. 
Table 1. (continued)

\begin{tabular}{lcc} 
& $\begin{array}{c}1971 \\
(N=1,053)\end{array}$ & $\begin{array}{c}1976 \\
(N=1,080)\end{array}$ \\
\hline $\begin{array}{l}\text { Question 44: Which statement most closely } \\
\text { reflects your opinion? }\end{array}$ & & \\
1. If you think it is better to sue, you may \\
$\begin{array}{l}\text { do so. } \\
\text { 2uing is not the most desirable action, } \\
\text { but you may use court-sponsored } \\
\text { mediation or formal discussion as much }\end{array}$ & 8.6 & 42.7 \\
$\begin{array}{l}\text { as you wish. } \\
\text { 3. You should try to avoid bringing suit } \\
\text { whenever possible and instead work to } \\
\text { resolve the matter through private } \\
\text { discussions. }\end{array}$ & 46.6 & 41.3 \\
4. Don't know/no answer. & 5.0 & \\
\hline
\end{tabular}

More relevant to the conventional understanding of Japanese legal culture as nonlitigious may be Questions 42,43 , and 44. Only a minority of respondents to Questions 42 and 44 gave positive responses regarding the use of litigation, a result supportive of the stereotype. However, the response to Question 43 also suggests a calculative basis for this aversion to litigation. What the researchers most emphasized was the drastic decline in the most positive response to Question 42 between 1971 and 1976 , as its percentage fell by one-half.

Several methodological problems in these surveys have been noted (Rokumoto, 1983a). Some questions were so abstract that the respondents were asked about matters most of them had never considered. Others, such as Question 43, encompassed more than one issue. These projects often used only one question for a very broad issue (e.g., Question 42 for the violation of rights and Question $\mathbf{4 4}$ for the use of courts) on which different responses could be expected under specific conditions. Certain questions also had response categories that were not mutually exclusive. For instance, among the answers to Question 32, a comfortable life (guai no yoi seikatsu) and the realization of justice (seigi no jitsugen) may coexist. In short, we may be skeptical about the validity of the results.

There is also a problem of reliability. Consider Question 42, for example. While the second survey repeated the same question to a representative sample in the same area only five years after the initial survey, the percentage share of the first response category became one half. Considering the very general character of the question, this change may raise doubts about the reliability of the entire project. Should we believe that the Japanese became more conservative so abruptly?

Most importantly, these two NBK projects are not directly 
relevant to our renewed interest in Kawashima's concept of legal consciousness, namely what Rokumoto called legal conception and rights conception. According to Rokumoto's explication, we have to measure the general normative framework that forms the basis of, for example, relaxed views on the bindingness of contracts or unwillingness to sue. This is not a fault of the NBK projects, which were planned before Rokumoto's explication. But it is nonetheless a problem we must face.

Table 2 presents data from the $\mathrm{KDH}$ project. The survey, which was conducted in 1977, was the first to use a national sample $(N=1,601)$. The Kyoto project's questionnaire was an improvement over those used in the NBK projects. Questions were less ambiguous and several were constructed to measure a single subject under different conditions. Another new device was to present both questions regarding conflict management in general and questions regarding the use of courts and legal professionals in particular so that the former would be correlated with the latter. (In Table 2, Questions 20 and 21b are the first type and Questions 22 through 26 are the second.)

The responses to Questions 22 through 26 suggest several conclusions. When a problem involves a continuing social relationship, the trouble is most likely to be ignored and a court is least likely to be used (Questions 24 and 25). The greater the actual or potential damage, the more likely it is that the court and the legal profession will be used (Questions 23 and 26).

Unfortunately, no scale was constructed for Questions 22 through 26 in spite of its obvious feasibility, and the responses to these questions were not correlated with those to Questions 20 and $21 \mathrm{~b}$. However, when the responses to Questions 20 and $21 \mathrm{~b}$ were correlated with answers to questions regarding the handling of an improperly issued traffic ticket and a defective toy, those who answered that they would present the problem to the other party or that they would seek a logical solution more often indicated that they would bring such matters to the court.

We now know that more thorough questionnaires are required to test Kawashima's thesis. Answers to Questions 22 through 26, for instance, do not indicate whether the respondents' aversion to courts was based on a general cultural framework or on rational calculation. We must thus devise new ways of dealing with Kawashima's concept, and we definitely need a scale of legal consciousness. Eysenck's (1954) scale of conservatism-in which he infers conservatism from responses to questions on ethnocentrism, child rearing, religion, patriotism, and the like-is a possible model. It may be impossible to agree on 
Table 2. Selected Questions from the Kyoto Daigaku Hogakubu Survey (in percent)

$(N=1,601)$

Question 20: What would you do if you had problems

with your neighbor?

1. Clearly present the problems to my neighbor.

2. Restrain myself to prevent further trouble.

3. Depends on the problems.

4. Don't know.

Question 21b: Which of the following solutions for conflicts and problems with others would you favor?

1. Make it clear which is right and which is wrong, and seek a logical solution.

2. Seek a solution that fits the nature of the trouble.

3. Can't choose.

4. Don't know.

\begin{tabular}{|c|c|c|}
\hline Case & $\begin{array}{l}\text { Action to Take } \\
\text { (percent) }\end{array}$ & $\begin{array}{c}\text { Mediator to Call } \\
\text { (percent) }\end{array}$ \\
\hline $\begin{array}{l}\text { Question 22: My six-month- } \\
\text { old refrigerator does not } \\
\text { work well and the store } \\
\text { refuses to exchange it for a } \\
\text { new one. }\end{array}$ & $\begin{array}{lr}\text { 1. } & 4.2 \\
\text { 2. } & 60.6 \\
\text { 3. } & 19.2 \\
\text { 4. } & 8.9 \\
\text { 5. } & 7.1\end{array}$ & $\begin{array}{lr}\text { 1. } & 36.6 \\
2 . & 2.8 \\
\text { 3. } & 20.4 \\
\text { 4. } & 11.9 \\
\text { 5. } & 28.2\end{array}$ \\
\hline $\begin{array}{l}\text { Question 23: After my new } \\
\text { house was built, I was asked } \\
\text { to pay } 1 \text { million more } \\
\text { than the initial estimate. }\end{array}$ & $\begin{array}{lr}\text { 1. } & 3.6 \\
\text { 2. } & 46.8 \\
\text { 3. } & 22.7 \\
\text { 4. } & 18.1 \\
\text { 5. } & 8.7\end{array}$ & $\begin{array}{lr}\text { 1. } & 31.1 \\
2 . & 5.0 \\
\text { 3. } & 11.5 \\
\text { 4. } & 30.4 \\
\text { 5. } & 21.9\end{array}$ \\
\hline $\begin{array}{l}\text { Question 24: My child was } \\
\text { injured while playing in the } \\
\text { schoolyard and received a } \\
\text { small scar on her face. }\end{array}$ & $\begin{array}{lr}\text { 1. } & 30.4 \\
2 . & 35.6 \\
3 . & 15.8 \\
\text { 4. } & 6.1 \\
\text { 5. } & 12.1\end{array}$ & $\begin{array}{lr}\text { 1. } & 26.7 \\
\text { 2. } & 6.8 \\
\text { 3. } & 14.0 \\
\text { 4. } & 13.4 \\
\text { 5. } & 39.2\end{array}$ \\
\hline $\begin{array}{l}\text { Question 25; The piano } \\
\text { teacher next door plays } \\
\text { unbearable noise after } 9 \text { P.M. }\end{array}$ & $\begin{array}{lr}\text { 1. } & 18.6 \\
\text { 2. } & 52.2 \\
\text { 3. } & 15.6 \\
\text { 4. } & 4.9 \\
\text { 5. } & 8.7\end{array}$ & $\begin{array}{lr}\text { 1. } & 32.1 \\
2 . & 7.7 \\
\text { 3. } & 20.1 \\
\text { 4. } & 9.2 \\
\text { 5. } & 30.8\end{array}$ \\
\hline $\begin{array}{l}\text { Question 26: My brand-new } \\
\text { television caught fire, but I } \\
\text { extinguished it before it } \\
\text { burned more than a small } \\
\text { portion of my room. }\end{array}$ & $\begin{array}{rr}\text { 1. } & 2.0 \\
\text { 2. } & 41.8 \\
\text { 3. } & 22.7 \\
\text { 4. } & 25.3 \\
\text { 5. } & 8.1\end{array}$ & $\begin{array}{lr}\text { 1. } & 20.1 \\
2 . & 2.9 \\
\text { 3. } & 31.3 \\
\text { 4. } & 23.0 \\
\text { 5. } & 22.7\end{array}$ \\
\hline
\end{tabular}

${ }^{a}$ Action to Take: 1. Do nothing.

2. Negotiate with the other party; no further action.

3. Ask someone to mediate; no further action.

4. If (2) and (3) failed, file suit or use court action.

5. Don't know.

'Mediator to Call: 1. Relative, friend, or other familiar person.

2. Local legislator or other official.

3. Administrative agency or police.

4. Attorney or other legal professional.

5. Can't choose. 
a single question that would measure legal consciousness. However, we may still be able to form a rough consensus on specific situations that can be regarded as expressions of Japanese legal consciousness.

A more ambitious project would construct a scale to be used in cross-national, comparative analysis. After all, any one country's culture can be characterized only in relation to other cultures. For instance, following Kawashima strictly, it may be interesting to construct scales of specificity-universality and informality-formality for the standards to be applied in dispute processing. Considering the extremely abstract character of Kawashima's rights consciousness, Rokumoto (1986b: 298) has recently proposed a less abstract concept of "rule-orientedness." One may expect that its operationalization will also result in the construction of a scale.

The next task is to use legal culture as thus measured to explain the activities of the formal legal system at the aggregate level. Just as we use individual attitudes to explain individual behavior, we may think of using aggregate-level culture to explain aggregate-level behavioral patterns such as the litigation rate.

In this regard, many people may consider trying to explain cross-national differences in the operation of the formal legal system by differences in national legal cultures measured by uniform scales. I am skeptical about such research, however. Reliance on official statistics is inevitable in this work, but the comparability of such data is always problematic (Sarat and Grossman, 1975). Furthermore, to avoid Kawashima's tendency of directly connecting legal culture to indices or anecdotes of systemic operation, we need to control other relevant variables. I suspect that some are extremely difficult to measure with uniform scales. For instance, what is the American equivalent of the nonattorney legal specialists found in Japan? How does one deal with doctrinal differences that limit access to the formal legal system independent of legal culture?

$\mathrm{My}$ plan is to conduct an interregional comparison of Japan. We need not worry much about legal culture if it does not help explain the operation of the formal legal system. If regional variations in legal consciousness are discovered and if, after proper control, such differences are found to be related to regional variations in the operation of the legal system, we may say at least that legal culture is significant.

Tanase's (1977) analysis on the determinants of the per capita rate of pro se civil litigation is instructive in this regard. After an analysis of official statistics for Japanese prefectures, 
he concludes, contrary to a commonsensical expectation that the per capita number of attorneys is inversely correlated with the rate of pro se litigation, that the rate of pro se litigation is in fact determined by per capita income. The higher the income, the lower the rate of pro se litigation. What we should do, therefore, is to examine whether the introduction of regional legal culture, measured in terms of majority responses to uniform scales, affects the relative impact of socioeconomic and institutional factors on this rate. I believe such a project is feasible.

\section{INDIVIDUAL ATTITUDES AND BEHAVIOR IN DISPUTE RESOLUTION}

No one has seriously explored legal consciousness as an attitudinal factor of individual behavior in empirical research. This is somewhat surprising since even in Japan longitudinal studies on the relationship between attitudes and behavior are no longer unusual. Indeed, such studies are quite common in the research on political behavior, particularly voting behavior, conducted by political scientists who are, at most Japanese universities, members of law faculties.

I do not mean, however, that there have been no major empirical studies of individual behavior in dispute resolution. In fact, I would like to summarize three examples. Sasaki's book on mediation in the court (1974) was probably the first attempt by any Japanese scholar to criticize the stereotype of Japanese legal behavior. The first edition of his book appeared in 1967, when Kawashima's Nihon-jin no Ho-ishiki [The Japanese Legal Consciousness] was also published. From 1958 through 1961, Sasaki conducted mailed questionnaire surveys of 2,034 residents of Shimane prefecture and 2,411 city residents of Osaka prefecture; examined the records of all civil mediation cases processed in 1957 by a district court in Shimane (441 cases) and a district court and a summary court in Osaka (2,944 cases) and conducted mailed questionnaire surveys of the parties of those cases (384 in Shimane and 1,811 in Osaka); and conducted mailed questionnaire surveys of 74 volunteer mediation commissioners in Shimane and of 82 in Osaka. It is easy to criticize the use of mailed questionnaires that do not guarantee the identity of respondents. However, because these surveys were carried out almost thirty years ago in Japan about a subject considered confidential, they were quite a heroic effort.

Tables 3 and 4 present some of Sasaki's data. The responses to the question on the willingness to use the court (see 
Table 3) give the impression that Sasaki's subjects were more willing to do so than the more contemporary subjects of Table 1 and Table 2. "Court" here meant litigation. Reasons 2 through 4 for the negative responses to the use of courts may be closest to the conventional notion of traditional Japanese legal consciousness. Rural residents were more afraid of the reactions of the other party and neighbors than were urbanites, a result that might be taken as support for both the conventional view as well as for my proposal that we initiate interregional comparative studies of activities of the formal legal system.

However, the main point of these findings is that the most frequent reasons given for avoiding litigation concerned the costs involved rather than beliefs rooted in the traditional consciousness. The issue is how disputes can be resolved if litigation is not used; court-sponsored mediation may be one means. In other words, the public may see mediation as a substitute for litigation in realizing legally justifiable interests rather than as a mechanism for realizing conventionally assumed purposes such as restoring harmonious social relationships.

The data on complaints heard from the parties who had actually been involved in mediation might be cited to support this interpretation (see Table 4). These parties sought mediation expecting both more involvement from the judge, who is nominally the chairman of the mediation commission, and binding resolutions based on more complete investigations of the facts (for similar observations regarding family court mediation, see Bryant, 1984). The reality of mediation, however, is that most cases are handled only by lay commissioners and that the commission does not have authority to make a binding decision. Presented this way, Sasaki's project should have attracted more attention as a study on individual attitudes and behavior in dispute resolution.

Unfortunately, Sasaki did not ask the involved parties their specific reasons for choosing mediation. We cannot be sure to what extent we can infer the existence of a high degree of interest consciousness behind behavior seeking mediation. The first attempt to reconstruct individual dispute processes retrospectively did not occur in Japan until 1968, when Rokumoto conducted his dissertation research (1971).

Rokumoto wanted to discover the factors that determined the degree of the legalization of social ordering in Japan. He defined legalization as the process through which society comes to rely increasingly on the formal legal system to maintain order. He first sent a card asking a representative sample of 2,013 residents of the Bunkyo ward of Tokyo if they had been in- 


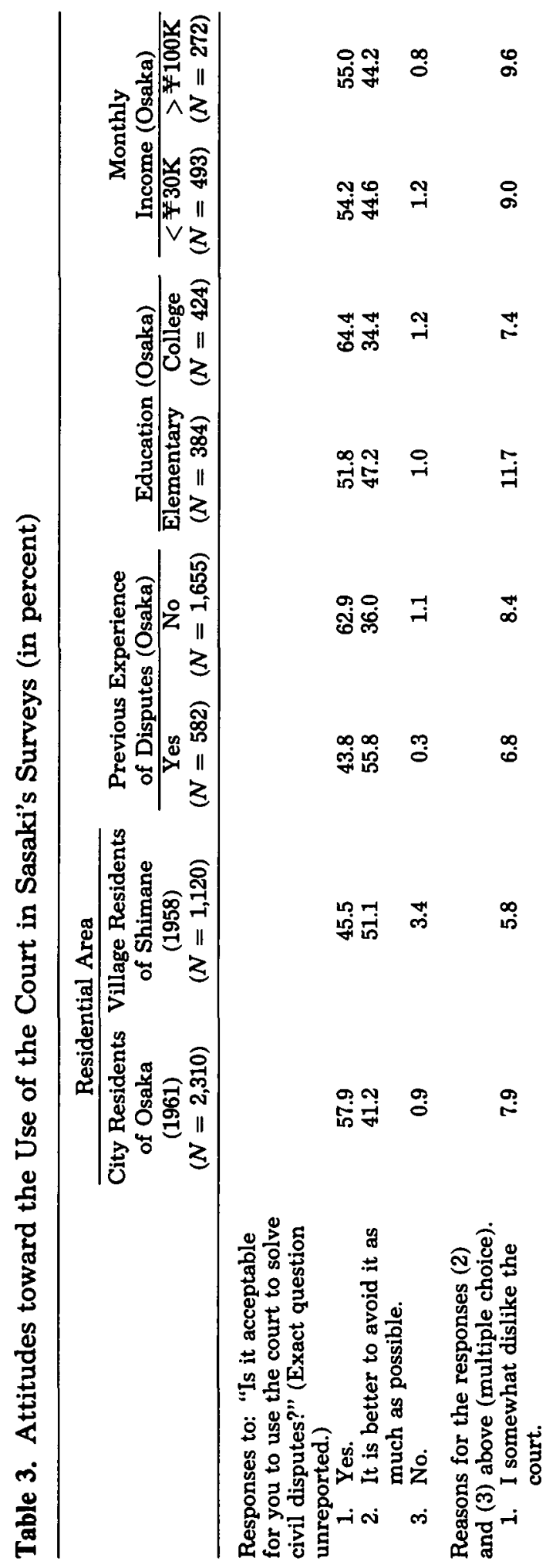


ปี่

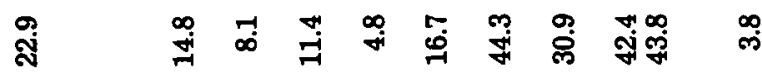

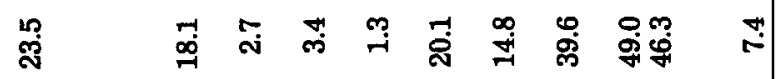

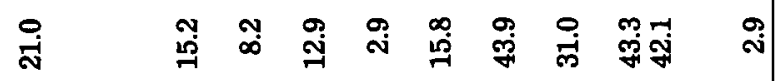

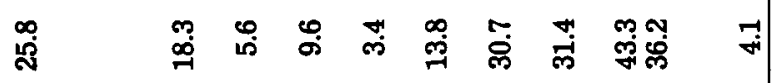

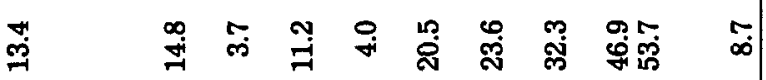

启

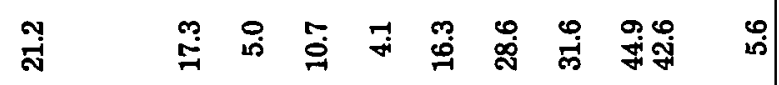

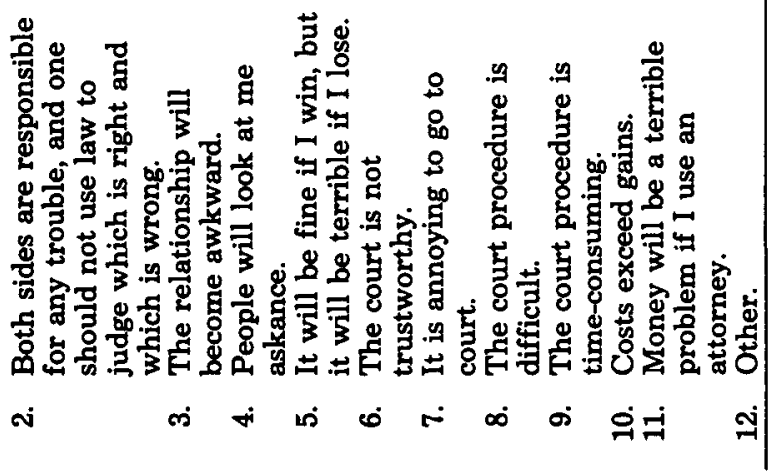


Table 4. Complaints about the Mediation Process by the Complaining Party in Sasaki's Surveys (in percent)*

\begin{tabular}{lcc}
\hline & $\begin{array}{c}\text { Shimane (1959) } \\
(N=210)\end{array}$ & $\begin{array}{c}\text { Osaka (1961) } \\
(N=365)\end{array}$ \\
\hline 1. The mediation commissioners did not fully & & \\
understand the situation. & 11.4 & 33.4 \\
2. The judge should hear the case by himself more & & \\
often. & 14.3 & 25.2 \\
3. The commissioners were not impartial. & 8.1 & 9.0 \\
4. The commissioners believed the respondent's lie. & 19.0 & 20.0 \\
5. The commissioners should make their proposals & & 21.0 \\
after more investigation. & 35.3 \\
\hline
\end{tabular}

* Some made no complaint in Shimane, while some made more than one complaint in Osaka.

volved in automobile accidents or housing disputes. He then interviewed 103 of the 226 respondents who answered affirmatively. Rokumoto reported data on forty-five accident cases and forty housing cases. Only three of the accident cases reached a court, while eleven of the housing cases went to litigation and another eleven went to mediation. Attorneys were used in only three accident cases but in thirty housing cases. Seemingly against the conventional view of the role of local officials in Japan, local politicians and police did not play any significant role in these cases. Instead, particularly in accident cases, nonattorneys who were nevertheless specialists in automobile accidents, such as insurance agents and accident managers of taxi companies, figured conspicuously as agents for parties, thus raising the possibility that these specialists sometimes engaged in the arbitrary manipulation of legal rules, exploitation of ignorant opponents, or deceit. The outcomes of these cases indicated that the parties who retained attorneys or specialists could expect favorable results.

Rokumoto's main argument is that the chance to obtain the assistance of attorneys and specialists and hence to mobilize the formal legal system to one's advantage is unevenly distributed in society. The people with the greatest advantage are those who are by occupation repeat users of legal specialists, most notably professional landlords (a result that reminds us of Mayhew and Reiss's work [1969] to which Rokumoto in fact refers). Those with the second greatest advantage belong to natural networks that include legal specialists. For those outside these groups, it is difficult to obtain legal counsel in Japan. Even when one is able to retain legal representation, parties without a previous relationship with the specialists, however indirect, will often find it hard to receive full, personal service.

As for legal consciousness, even mediation is a deliberate 
attempt to enforce one's legally protected interests. In some cases, mediation is used to block the use of litigation by the other party, whose legal basis may be much stronger. In contemporary Japan, at least in urban areas, parties use both mediation and litigation to pursue their own interests. These results apparently differ from a commonsensical version of the Kawashima thesis.

However, Rokumoto does not regard such interest-mindedness as the truly modern legal consciousness. Instead, he implies that this thinking lacks internalization of universalistic standards, acceptance of the reciprocity of right-duty relationships, and reliance on the court as an objective adjudicator. Indeed, the mobilization of law does not necessarily reflect legal consciousness, even in the sense of interest-mindedness. After all, if one happened to be in one of those networks mentioned above, the assistance of legal specialists would naturally be provided. In light of this argument, it seems logical that Rokumoto tries to resurrect Kawashima's conception of legal consciousness through his explication.

The second example of a retrospective analysis of disputing behavior is Wada's (1983-84) recent work. Using an expanded version of Felstiner et al.'s (1980-81) model of the formation and transformation of grievances, he first sent a questionnaire to a representative sample of 976 residents of a Tokyo suburb in 1982. He asked if they had been involved in "troubles" (mondai) in any of ten specified fields. He interviewed 169 of the 312 respondents who answered affirmatively. The data were presented for 107 .

Wada distinguished six stages of grievance transformation, in the following progression: (1) an injurious experience is perceived (PIE); (2) someone is blamed and a PIE becomes a grievance; (3) the claiming party makes a demand and the grievance becomes a claim; (4) the responding party rejects the claim and a dispute issues; (5) the claiming party makes a second claim and a negotiation starts; and (6) one party resorts to mediation, arbitration, or even litigation. Almost three-quarters of all cases ended before the negotiation stage. Grievances most frequently involved neighbors (33 cases), but two-thirds of the neighbor cases ended before the dispute stage. The second largest group of cases involved grievances about housing or land tenancy (14 cases). Unlike other types of cases, half of these reached at least the negotiation stage, and two cases reached the court. Wada's findings are thus consistent with Rokumoto's data on housing disputes.

Wada tried to identify the factors that determined how far 
a grievance would proceed in this transformation process. He distinguished three types of factors: (1) relational factors, or the effects of the ongoing social relationships between the parties; (2) technical factors, or the party's subjective knowledge about law, the objective legal merits of the case, and his or her realistic chance of winning; and (3) value factors, or the magnitude and urgency of the grievance. He concluded that value and relational factors carried greatest weight in earlier stages of the transformation process, causing smaller, neighborhood or family cases to drop out at these stages. If a case reached the dispute stage, technical factors started to dominate. At the negotiation and court stages, technical factors such as the objective merit of the case or the realistic likelihood of winning became almost the only determinants. It should be easy to see a link between Wada's findings and Rokumoto's data on the importance of the availability of technical assistance. Wada did not say much about legal consciousness or attitudinal factors. We again receive the impression that they do not much matter and that the processing of individual grievances can be explained almost totally by objective factors.

But such impression may well be an artifact of Rokumoto's and Wada's research designs. Because they retrospectively collected information on dispute processing, they did not have a chance to measure attitudes directly before grievances materialized or to relate previously measured attitudes to later behavior. I conclude, therefore, that the importance of individual attitudes as explanatory variables for individual dispute behavior has not yet been seriously studied, much less resolved. This, I believe, is where research efforts should be directed.

I am in the most preliminary stage of a project on this subject. It is clear, however, that I will have to design a longitudinal study with at least two measurements of the same sample. In the first survey, for instance, I should measure the respondents' attitudes regarding law and their place in networks that would make specialists available for various types of disputes. The second survey would then retrospectively ask if any disputes had arisen, how they had been handled, and for what reasons. Sociological characteristics of the respondents and their relationship with the other party should also be analyzed in terms of such variables as stratification, morphology, cultural conventionality, and the availability of nonlegal forms of social control under given social relationships (Black, 1976).

The history of social-psychological studies of attitude-behavior relationships indicates the need for caution. Since LaPiere's classical study (1934) of the inconsistency between 
verbally expressed ethnic discrimination of hotel and restaurant operators and their actual responses to Chinese persons, research on attitude-behavior relationships has consistently demonstrated the discontinuity of such relationships. One way to increase correlations between attitudes and behavior is to construct a scale of general features of behavior on the basis of multiple instances of behavior (Fishbein and Ajzen, 1974) and correlate attitudes with such a scale rather than with a single instance of behavior. However, exactly because the disputing behavior is likely to be infrequent, such a strategy is not feasible.

We could approach the problem from the other side of the attitude-behavior nexus by developing a scale of legal attitudes. Eysenck's conservatism scale may again be a model. I suspect, however, that in constructing a scale for this purpose, the highly abstract nature of Kawashima's concept of legal consciousness is likely to be unproductive at an individual level. Social psychologists have argued that if we want to explain specific instances of behavior, we should measure attitudes toward stimuli directly related to the given behavior (Fishbein and Ajzen, 1975). Although Rokumoto (1986b: 298) has recently proposed translating Kawashima's concept into less abstract terms, he has not yet achieved this goal, and his concept of rule-orientedness itself seems fairly abstract.

Of course, it is impossible to construct a scale at a level exactly the same as that of daily stimuli. But we may still try to list a sample of situations in which the use of the formal legal system might at least be one possible response. This also means, however, that given a realistic limitation on the size of the questionnaire, we should study just one small sphere of daily life at any given time. If (and this is a big "if" considering the current state of Japanese law and society scholarship) many researchers approached many different areas of life with similar instruments, such a piecemeal examination would gradually give us a fuller understanding of the entire picture.

If this approach were taken, what would happen to the study of aggregate-level culture? I believe that aggregate-level culture can be introduced into individual-level analysis as a social interactive factor. I of course mean to borrow from Mead's (1934) notion of the generalized other. The generalized other may be translated into empirical terms as prevailing, dominant expectations and attitudes held by a majority of members of a given group or a region. Because any injurious experience is a breakdown of the order of injured persons' routines, they must first find a definition of the harmful situation and then a defini- 
tion of their proper responses to it. Their own attitudes may be an important source of such definitions. However, exactly because such an experience is infrequent, the people may want to refer to what others think or would think about the situation either to define the situation and their responses or to justify personal definitions. Indeed, part of the impact of the legal specialists Rokumoto found may be in providing such definitions. If so, during the first survey of our longitudinal study, we should measure how respondents perceive the dominant views about different forms of injurious experience among the people around them. We should consider the respondents' perceptions of the views of people at several layers of proximity, starting probably with family members. Ideally, we should have a sample from different regions, the cultures of which we would already have surveyed. In the second survey, we would ask respondents what they actually referred to in making decisions. In the final analysis, respondents' previous perceptions, references during the disputing process, and separately measured regional legal cultures would all be used as explanatory variables. Aggregate-level culture and individual-level attitude would thus be combined in one research project.

\section{CONCLUSION}

I have tried to reevaluate my Japanese colleagues' studies in light of explications of the Kawashima thesis with regard to both the meaning of the concept of legal consciousness and its dual status as group culture and an individual attitudinal factor. I have also offered general ideas about possible empirical research on the basis of these studies. I am afraid, however, that I have presented Kawashima too seriously to international colleagues, most of whom are not likely to be familiar with him, and that I have been too behavioristic. In fact, I am not a student of Kawashima nor particularly behavioristic in my previous works, which instead display a strongly organizational approach, with a touch of interactionist perspective in my emphasis on participant observation as a research method (Miyazawa, 1985a, 1985b, 1985c).

I nonetheless wanted first to give international colleagues a sense of what is going on in Japanese law and society scholarship. I then chose a behavioristic approach exactly because it has been absent in research on Japanese legal consciousness. I wanted to break the stereotype of a Japanese scholar adopting an anecdotal approach. Another, more essential reason for my behavioristic approach was my desire to spur international 
scholars to conduct serious empirical research in Japan. Even recent studies on Japan abound with exoticism. For instance, even Ames's (1981) fine book on Japanese police describes too often a stereotypical samurai instead of presenting supposedly rich observational data gained from his study of police stations for over a year. What we need is research that does not explain away Japan by attributing every finding to "Japanese uniqueness" but instead applies theories and methods that treat Japan as a point on a universal continuum.

In this regard, it should be remembered that Eysenck's scale was used by an American political scientist to measure legal conservatism in Japan: Dator (1969) administered the scale to none other than Japanese Supreme Court justices and high court judges. Although Dator did not use his results to explain the judicial behavior of those justices and judges, he at least gave us hope that a behavioristic approach could be applied in studies of law and society in Japan. Colleagues from around the world should try an approach that combines an observational, qualitative method with a behavioral, quantitative method to achieve this goal.

\section{REFERENCES}

AMES, Walter L. (1981) Police and Community in Japan. Berkeley: University of California Press.

BLACK, Donald (1976) The Behavior of Law. New York: Academic Press.

BRYANT, Taimie L. (1984) "Marital Dissolution in Japan," 17 Law in Japan 73.

CURRAN, Barbara A. (1977) The Legal Needs of the Public. Chicago: American Bar Foundation.

DATOR, James Allen (1969) "Measuring Attitudes across Cultures," in G. Schubert and D. J. Danelski (eds.), Comparative Judicial Behavior. New York: Oxford University Press.

EYSENCK, Hans J. (1954) The Psychology of Politics. London: Routledge and Kegan Paul.

FELSTINER, William L. F., et al. (1980-81) "The Emergence and Transformation of Disputes," 15 Law \& Society Review 631.

FISHBEIN, Martin, and Icek AJZEN (1975) Belief, Attitude, Intention and Behavior. Reading: Addison-Wesley.

- (1974) "Attitudes towards Objects as Predictors of Single and Multiple Behavioral Criteria," 81 Psychological Review 59.

FRIEDMAN, Lawrence M. (1977) Law and Society. Englewood Cliffs, NJ: Prentice-Hall.

- (1975) The Legal System. New York: Russell Sage Foundation.

GALANTER, Marc (1983) "Reading the Landscape of Disputes," 31 UCLA Law Review 4.

GIBSON, Dale, and Janet K. BALDWIN (1985) Law in a Cynical Society? Calgary: Carswell.

HALEY, John Owen (1982) "The Politics of Informal Justice," in R. Abel (ed.), The Politics of Informal Justice, Vol. 2. New York: Academic Press. (1978) "The Myth of the Reluctant Litigant," 4 Journal of Japanese Studies 359. 
HARVARD LAW REVIEW (1981) "Note: Rethinking Regulation," 94 Harvard Law Review 1871.

JOHNSON, Chalmers (1982) MITI and the Japanese Miracle. Stanford: Stanford University Press.

KAWASHIMA, Takeyoshi (1982) Kawashima Takeyoshi Chosaku-shu [Collected Writings of Kawashima], Vol. 4. Tokyo: Iwanami Shoten.

- (1974) "The Legal Consciousness of Contract in Japan," 7 Law in Japan 1.

(1967) Nihon-jin no Ho-ishiki [The Japanese Legal Consciousness]. Tokyo: Iwanami Shoten.

(1963) "Dispute Resolution in Contemporary Japan," in A. von Mehren (ed.), Law in Japan. Cambridge, MA: Harvard University Press.

KIDDER, Robert L. (1983) Connecting Law and Society. Englewood Cliffs, NJ: Prentice-Hall.

KIM, Chin, and Craig M. LAWSON (1979) "The Law of the Subtle Mind," 28 International and Comparative Law Quarterly 491.

KYOTO DAIGAKU HOGAKUBU [Kyoto University Faculty of Law] (1978) Ho-ishiki to Funso Shori [Legal Consciousness and Dispute Resolution]. Kyoto: Kyoto Daigaku Hogakubu.

LAPIERE, Richard T. (1934) "Attitudes vs. Actions," 13 Social Forces 230.

MAYHEW, Leon, and Albert J. REISS, Jr. (1969) "The Social Organization of Legal Contacts," 34 American Sociological Review 309.

MEAD, George H. (1934) Mind, Self and Society: From the Standpoint of a Social Behaviorist. Chicago: University of Chicago Press.

MIYAZAWA, Setsuo (1985a) Hanzai Sosa o meguru Dai-issen Keiji no Ishiki to Kodo [The Attitudes and Behavior of the First-Line Detectives Concerning Criminal Investigation]. Tokyo: Seibundo.

- (1985b) Organizational Adaptation to Multiple Environments. Ph.D. dissertation, Department of Sociology, Yale University.

- (1985c) "Professionalization of Legal Departments of Japanese Corporations in the U.S." Presented at the Law and Society Association Meeting, San Diego (June 6-9).

NIHON BENGOSHI RENGOKAI [Japanese Federation of Bar Associations] (1986) Shimin to Horitsu Mondai [Citizens and Legal Problems]. Tokyo: Dai-ichi Hoki.

NIPPON BUNKA KAIGI [Japan Culture Forum] (1982) Gendai Nihon-jin no Ho-ishiki [Legal Consciousness of the Contemporary Japanese]. Tokyo: Dai-ichi Hoki.

(1973) Nihon-jin no Ho-ishiki [The Japanese Legal Consciousness]. Tokyo: Shiseido.

OSAKA BENGOSHIKAI [Osaka Bar Association] (1977) Ho, Saiban, Bengoshi [Law, Litigation, and Attorneys]. Kyoto: Mineruva Shobo.

PODGORECKI, Adam, et al. (eds.) (1973) Knowledge and Opinion about Law. London: Martin Robertson.

RAMSEYER, J. Mark (1985a) "Consensus, Litigation, and the Legitimation of the Bureaucratic Rule in Japan." Presented at the Law and Society Association Meeting, San Diego (June 6-9).

- (1985b) "The Costs of the Consensual Myth," 94 Yale Law Journal 604.

ROKUMOTO, Kahei (1986a) Ho-shakaigaku [The Sociology of Law]. Tokyo: Yuhikaku.

- (1986b) "Nihon-jin no Ho-ishiki Saiho" [The Japanese Legal Consciousness Revisited], in R. Mochizuki et al. (eds.), Ho to Ho-katei [Law and Legal Process (Festschrift for Toshio Hironaka)]. Tokyo: Sobundo.

- (1983a) "Ho-ishiki no Sokutei" [Measurement of Legal Consciousness], in T. Yamaguchi (ed.), Tozai Ho-bunka no Hikaku to Koryu [Comparison and Exchange between Eastern and Western Legal Cultures (Festschrift for the 70th Birthday of Yoshiyuki Noda)]. Tokyo: Yuhikaku.

(1983b) "Nihon-jin no Ho-ishiki Kenkyu Gaikan" [A Survey of Research on the Japanese Legal Consciousness], 35 Ho-shakaigaku [The Sociology of Law] 14.

- (1971) Minji Funso no Ho-teki Kaiketsu [Legal Resolution of Civil Disputes]. Tokyo: Iwanami Shoten.

ROSENBERG, Morris J., and Carl I. HOVLAND (eds.) (1960) Attitude Organization and Change. New Haven: Yale University Press. 
SARAT, Austin, and Joel GROSSMAN (1975) "Courts and Conflict Resolution," 69 American Political Science Review 1200.

SASAKI, Yoshio (1974) Zoho Minji Chotei no Kenkyu [A Study of Civil Mediation], Enl. ed. Kyoto: Horitsu-bunka-sha.

SINGER, Milton (1968) "The Concept of Culture," in D. L. Sills (ed.), International Encyclopedia of Social Sciences, Vol. 3. The Macmillan \& Co. and the Free Press.

STEWART, Richard B. (1981) "Regulation, Innovation, and Administrative Law," 69 California Law Review 1256.

SUGIMOTO, Yoshio, and Ross MOUER (1982) Nihon-jin wa Nihon-teki ka [Are the Japanese Japanese?]. Tokyo: Toyo Keizai Shinpo-sha.

TANASE, Takao (1977) "Bengoshi no Chi-iki Bunpu to Honnin Sosho Ritsu" [Regional Distribution of Attorneys and the Rate of Pro Se Litigation], Pts. 1,2, 635, 636 Jurisuto 80; 120.

TOSHITANI, Nobuyoshi (1985) "Ho-ishiki no Genjo Bunseki no tameni" [For Analyzing the Present State of Legal Consciousness], 37 Ho-shakaigaku [The Sociology of Law] 1.

UPHAM, Frank K. (forthcoming) The Ideology of Informality. Manuscript. Cambridge, MA: Harvard University Press.

WADA, Yasuhiro (1983-84) "Nichijo no naka no Funso Shori" [Dispute Resolution in Everyday Life], Pts. 1, 2, 24:2, 25:1 Tokyo Toritsu Daigaku Hogakkai Zasshi [Tokyo Metropolitan University Journal of Law and Polities] 1. 
